\title{
JCIHE: Fall 2020 Introduction
}

\author{
Rosalind Latiner Raby \\ California State University, Northridge, USA \\ Email: rabyrl@aol.com
}

Dear Readers -

I am pleased to share the Fall 2020 issue of the Journal of Comparative and International Higher Education (JCIHE). JCIHE is an open access, independent, peer-reviewed international and multidisciplinary journal designed for advancing the field of comparative and international higher education. JCIHE has as its core principles: a) comparative and international research on higher education; b) engagement with theory; and c) diverse voices in terms of authorship. The journal serves as a place to share new thinking on analysis, theory, policy, and practice that relate to issues that influence comparative and international higher education. The JCIHE is the official journal of the Comparative and International Education Society (CIES) Higher Education Special Interest Group (HESIG).

The Fall 2020 issue includes eight articles that examine the intersection of institutional policies and pedagogical practices and the impact that they have on student learning and success. Three of the articles examine the ramifications of institutional practices on faculty output and on student learning. Heuser, Lyken-Segosebe, \& Braxton examine what English-speaking universities value in terms of faculty publication productivity across the Boyer's four domains of scholarship. Institutional policies of universities with the highest rankings value different domains than universities with the lowest level of rankings. Thompson, Clarke, Quickfall, \& Glazzard explore the connection between teacher trainee wellbeing and student retention in three European countries. Institutional practices in each country define different criteria for workload, peer relationships, and the quality of pedagogical knowledge, the 
combination of which contribute to or decrease teacher stress. In turn, decreased stress is directly related to student retention. Kwasi-Agyeman, Langa, \& Swanzy compare how universities in Ghana and South Africa are finding alternative institutional funding from international student fees and from distance education via Satellite campuses fees. The non-traditional funding is then used to counter diminishing public higher education funding. Ghazarian explores how different university stakeholders create or reinforce institutional policies that challenge the perceived importance and the perceptions of quality of internationalization in a university in the Republic of Korea. Karkour \& Jusseaume examine how weak institutional practices in a US university result in creating and sustaining an environment that does not promote deep personal connections and that then negatively impacts overall learning of international students. Bilas explores how weak institutional support services and practices negatively affect international student spouses in terms of their health care, housing, and outreach. Finally, Maruza, Langa, Augusto, \& Nkhoma detail institutional disability policy framing in African higher education to identify how different academic and professional disciplines influence policy and practice which, in turn, then effects student accommodations and learning.

A second theme found in the Fall 2020 issue is a critical assessment of when and how pedagogy actually allows learning to happen. Karkour \& Jusseaume find that intercultural sensitivity learning, that is presumed to occur as a result of student mobility, is limited for international students studying in a US university over one semester. They raise the question then if intercultural sensitivity learning can occur holistically or if it needs specific and directed instruction. Thompson, Clarke, Quickfall, \& Glazzard find that when trainee teachers in three European countries are taught conflict resolution and coping mechanism skills, they end up having a stronger learning environment for themselves and, in turn, for their students. Maruza, Langa, Augusto, \& Nkoma advocate for a new lens to explore alternative ways of understanding how disability policy in Africa creates or contributes to exclusions that truncate learning possibilities. Finally, Gülen \& Yadigar examine the adoption of 'fun books' by teacher trainees in Turkey 
to positively influence $\mathrm{K}-12$ students as well as influence higher education students in their note-taking skills, that in turn, allows them to better prepare for exams.

JCIHE is pleased to introduce the new International Advisory Board (2020-2022): Mark Ashwill, CapestoneVietnam; Yeow-Tong Chia, University of Sydney; Christopher Collins, Azusa Pacific University; Omolabake Fakunle, University of Edinburgh; Ali Said Ali Ibrahim, United Arab Emirates University; Dilrabo Jonbekova, Nazarbayev University, Kazakhstan; Mei Li, East China Normal University; Ka Ho Mok (Joshua), Lingnan University, Hong Kong; Daniela Perotta, University of Buenes Aires, Dante J Salto, University of Wisconsin-Milwaukee; and Sharon Stein, University of British Columbia. The International Advisory Board along with the Regional Editors are bringing a wide range of expertise to JCIHE that will help to provide new directions in advancing studies of comparative and international higher education.

I want to give special thanks to Dr. Gerardo Blanco, Boston University, who transitions off of the HE-SIG team and who served as the Executive Editor of the JCIHE. Dr. Blanco will continue with JCIHE as an Associate copy-editor and contributing manager. JCIHE welcomes the new JCIHE Executive Editors, Dr. Pilar Mendoza and Dr. Anatoly Oleksiyenko, who also serve as the co-chairs of the CIES HE-SIG. I would also like to welcome the new JCIHE Managing Editor, Nian Ruan (University of Hong Kong) and the new JCIHE Production Editor, Jade Liu (University of Hong Kong). Finally, I want to extend my sincerest thanks to the current JCIHE Managing Editor, Dr. Hei-hang Hayes Tang (Education University of Hong Kong) who has supported the journal in improving quality and focus. Dr. Tang will be transitioning to be the new JCIHE Associate Editor position.

As JCIHE growths in breadth and depth, it is important to continually refine a structure that is useable for our readership. As such, JCIHE as now adopted the APA $7^{\text {th }}$ edition for all manuscripts. In future issues, JCIHE will continue to recognize the importance of comparative and international higher educational themes in a variety of educational fields with the explicit aim to continually recognize 
emerging issues that cross national boundaries and to build new patterns of publishing help to better understand the state of our field.

Editor-in-Chief,

Rosalind Latiner Raby

Fall, 2020 